\title{
Participation in primary health care through community-level health committees in Sub-Saharan Africa: a qualitative synthesis
}

Robinson Karuga ${ }^{1,2^{*}} \mathbb{0}$, Maryse Kok ${ }^{3}$, Marthe Luitjens ${ }^{2}$, Patrick Mbindyo ${ }^{4}$, Jacqueline E. W. Broerse ${ }^{2}$ and Marjolein Dieleman ${ }^{2}$

\begin{abstract}
Background: Health committees are key mechanisms for enabling participation of community members in decision-making on matters related to their health. This paper aims to establish an in-depth understanding of how community members participate in primary health care through health committees in sub-Saharan Africa (SSA).

Methods: We searched peer-reviewed English articles published between 2010 and 2019 in MEDLINE, Popline and CINAHL databases. Articles were eligible if they involved health committees in SSA. Our search yielded 279 articles and 7 duplicates were removed. We further excluded 255 articles following a review of titles and abstracts by two authors. Seventeen abstracts were eligible for full text review. After reviewing the full-text, we further excluded two articles that did not explicitly describe the role of health committees in community participation. We therefore included 15 articles in this review. Two authors extracted data on how health committees contributed to community participation in SSA using a conceptual framework for assessing community participation in health. We derived our themes from five process indicators in this framework, namely, leadership, management and planning, resource mobilization from external sources, monitoring and evaluation and women involvement.
\end{abstract}

Findings: We found that health committees work well in voicing communities' concerns about the quality of care provided by health facility staff, day-to-day management of health facilities and mobilizing financial and non-financial resources for health activities and projects. Health committees held health workers accountable by monitoring absenteeism, quality of services and expenditures in health facilities. Health committees lacked legitimacy because selection procedures were often not transparent and participatory. Committee members were left out in planning and budgeting processes by health workers, who perceived them as insufficiently educated and trained to take part in planning. Most health committees were male-dominated, thus limiting participation by women.

Conclusion: Health committees contribute to community participation through holding primary health workers accountable, voicing their communities' concern and mobilizing resources for health activities and projects. Decision makers, health managers and advocates need to fundamentally rethink how health committees are selected, empowered and supported to implement their roles and responsibilities.

Keywords: Community participation, Health committee, Community engagement, Social accountability

*Correspondence: robinson.karuga@lvcthealth.org

${ }^{2}$ Athena Institute, Vrije Universiteit Amsterdam, De Boelelaan 1085, 1081

HV Amsterdam, The Netherlands

Full list of author information is available at the end of the article

\section{Background}

Community-level health committees are defined as any formally constituted governance structures with community representation with an explicit link to a primary 
health facility. The primary purpose of these health committees is to enable participation of community members in decision-making on matters related to improving health service provision and health outcomes [1]. Many countries have health committees, which have the potential to be effective structures for active community participation in pursuit of universal health coverage by monitoring progress, identifying and solving problems and re-planning health priorities [2, 3]. Since health committees consist mostly of individuals from the community, they focus on quality services for their community and local health priorities. In response to regional and global calls for community participation in the management of primary health care, Ministries of Health in developing countries, in the early 1990s, established health committees to enhance participation of communities in the planning and development of primary health care and education programs [4]. Various forms of health committees exist. There are those health committees where lay community members participate in overseeing 1) the delivery of health services at household level, and 2) the management of primary health services in local primary health facilities.

Community participation in making oversight of primary health services contributes to improved health outcomes. A study by Loewenson et al. [5] in Zimbabwe demonstrated that health facilities that had a health committee had 1) more resources (financial and staff), 2) fewer drug stock outs, and 3) a higher coverage of primary health care services (6). In addition, the communities living within the area of coverage had better health knowledge and utilization of primary health services [5]. A study by Sohani et al. (2005) in Kenya demonstrated that health facilities with active health committees had better utilization of health services. This was associated with the health committees' role in managing user fees, shaping local policy, recruiting and motivating community health workers (CHWs), providing healthcare education, establishing weekend outreach services for the remote villages, and increasing the availability of medicines [6].

Most countries in Sub-Saharan Africa (SSA) aspire to achieve universal access to healthcare for their citizens. Involvement of communities, through health committees, in the delivery of primary health services is essential for countries to achieve this aspiration [7, 8]. There is, however, limited knowledge on how health committees contribute to community participation in SSA [1]. Draper et al. [9] promulgated a conceptual framework to standardize the evaluation of community participation levels and processes in health programs using five process indicators: leadership, planning and management, women's involvement, mobilization of external resources, and monitoring and evaluation. Since this framework focuses on different process indicators of community participation, it allows us to conduct a nuanced analysis of how health committees contribute to community participation [9]. The Draper et al. [9] framework proposes three levels of participation in the community participation continuum, and for each process indicator. The lowest level is "mobilisation". At this level of the continuum, health professionals run primary health programmes and only mobilize community members for actions and to passively support decisions. The second level of participation is "collaboration". In this level of participation, health professionals define primary health care needs of the community and invite them to contribute their personal resources and time in health promotion activities. The highest level of community participation in the continuum is referred to as "empowerment", where community members have opportunities to exercise their power to make decisions that affect their health [9].

Operationalization and scale-up of community participation in health, including through health committees, is challenging and knowledge is rather fragmented. Therefore, increased insight into how health committees contribute to community participation will inform policy makers and health managers about the dynamics of community participation, through health committees, and how participation contributes to outcomes of community health programs [9]. This paper aims to establish an indepth understanding of how community members participate in primary health care through community level health committees in SSA.

\section{Methods}

We conducted a systematic review of qualitative studies in SSA to get an in-depth understanding of the features of health committees and how they contribute to community participation across a wide range of settings. Synthesis of qualitative evidence is helpful for interpreting and understanding subtle narratives on experiences and perceptions of actors involved in community participation within their contexts [10]. This section describes the procedures we followed.

\section{Search methods for studies in this review}

In September 2019, we systematically searched for original peer-reviewed qualitative studies conducted in SSA. We included articles that applied mixed methods when they clearly described the qualitative research components. For studies to be eligible, they had to present an analysis of how health committees participated in health and had to be published in English between 2008 and 2019. We first searched the MEDLINE database using search terms that covered population (research 
conducted in SSA), concept (research related to community-level health committees), and context (primary health care settings in SSA) [11]. We then searched the Popline database before it was retired in September 2019 and CINAHL. The search terms are illustrated in Supplementary file 1 .

\section{Selection of studies}

Our database search identified a total of 279 articles. One author uploaded all articles from the database searches on to the Rayyan Systematic Reviews Web App (https:// rayyan.qcri.org/). Two authors (ML and RK) independently assessed the titles of articles to identify the ones that fit into this review by examining the subject and where the research was conducted. Seven duplicates were identified and deleted at this phase of screening. From the remaining 272, abstracts of articles that seemed relevant were read by two researchers to assess whether their research questions, study populations and methodologies aligned with the inclusion criteria of this review. As a result, we excluded 255 articles because they were not about health committees. ML and RK then examined the full text of the 17 articles that met the eligibility criteria for further screening. Any conflicts at each step of screening were discussed among the two authors until consensus was reached. We further excluded two articles that did not explicitly describe the role of health committees in community participation. Fifteen articles were included in this review. The flowchart in Fig. 1 summarizes the selection process. We then transferred all eligible articles into the EndNoteX7.5 reference management software.

\section{Data management, extraction and analysis}

We began by extracting data on the first author, year of publication, study setting and a summary of the study from the identified papers. Two reviewers then conducted an in-depth data extraction on how health committees contributed to community participation in SSA using the conceptual framework proposed by Draper et al. [9] for assessing community participation in health. The two reviewers (RK and ML) independently read all the articles that were eligible for inclusion in this review. Any discordances between the reviewers during article selection and data extraction process were resolved during weekly analysis meetings. We derived our themes from the five process indicators in this framework, namely, leadership, management and planning, resource mobilization from external sources, monitoring and evaluation, and women involvement (Table 1). We deductively coded text from the research articles in the five themes using Microsoft Excel. Where extracted data seemed to fit in more than one theme, we agreed on the most relevant theme to fit it in. Three authors discussed the synthesis of evidence for one theme at a time.

\section{Results}

We start this section by providing an overview of the articles included in this review. We then describe how health committees contribute to community participation.

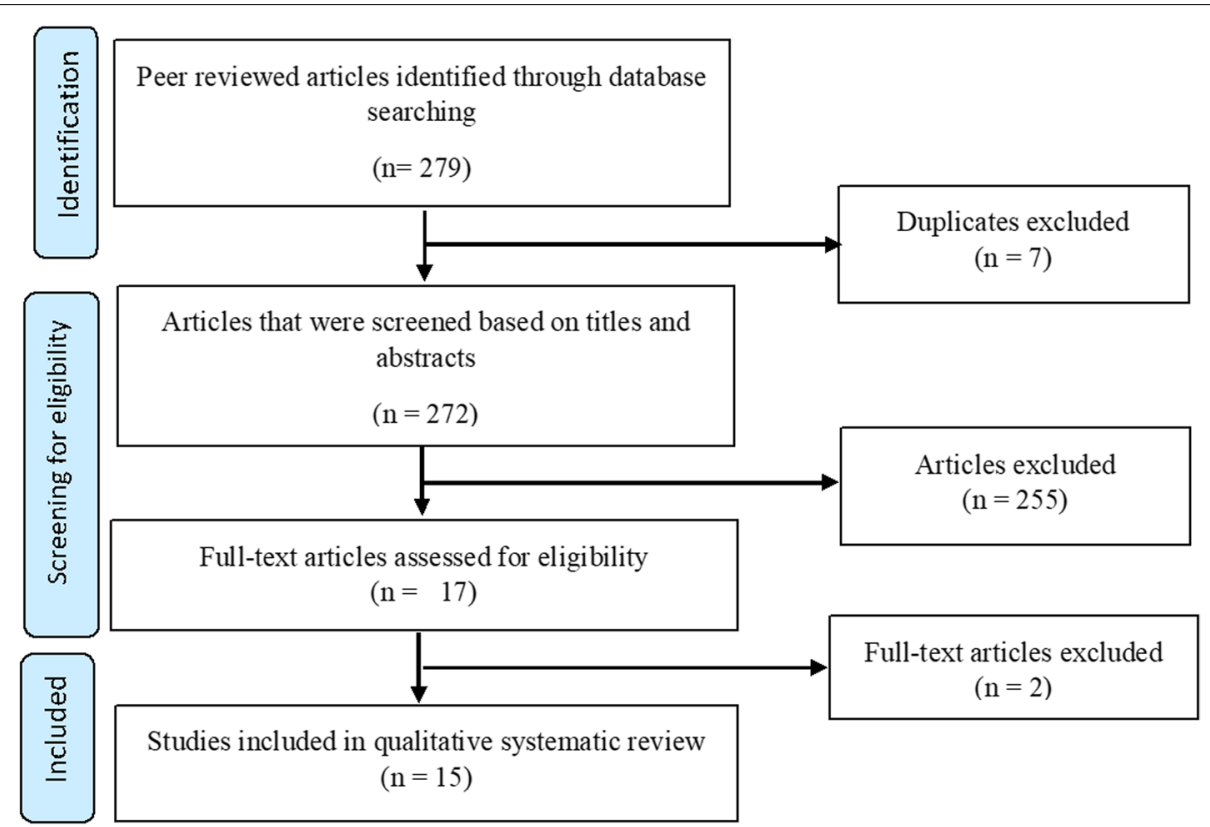

Fig. 1 Flow Chart summarizing the process of selecting articles to include in this review 
Table 1 Definition of process indicators in our conceptual framework [9]

\begin{tabular}{|c|c|c|}
\hline Themes & Definition of process indicators & $\begin{array}{l}\text { Number of articles } \\
\text { contributing to each } \\
\text { theme }\end{array}$ \\
\hline Leadership & $\begin{array}{l}\text { The extent to which health committee members provide leadership in decision-making and } \\
\text { how interests of various community groups are represented through health committees }\end{array}$ & $\begin{array}{l}10 \\
{[12-21]}\end{array}$ \\
\hline Management and planning & $\begin{array}{l}\text { The extent to which health committee members define priorities and manage community } \\
\text { health services. }\end{array}$ & $\begin{array}{l}10 \\
{[13-15,17,20-24]}\end{array}$ \\
\hline $\begin{array}{l}\text { Resource mobilization from } \\
\text { external sources }\end{array}$ & $\begin{array}{l}\text { The extent to which health committee members find ways of mobilizing resources for running } \\
\text { health-related activities at the community level. }\end{array}$ & $\begin{array}{l}6 \\
{[17,20-23,25]}\end{array}$ \\
\hline Monitoring and evaluation & $\begin{array}{l}\text { The extent to which health committee members conduct participatory evaluation of health } \\
\text { services that produce local meaningful findings. }\end{array}$ & $\begin{array}{l}5 \\
{[16,17,20-23]}\end{array}$ \\
\hline Women involvement & $\begin{array}{l}\text { The extent to which women actively participate in decision-making through the health com- } \\
\text { mittee }\end{array}$ & $\begin{array}{l}4 \\
{[12,13,22,26]}\end{array}$ \\
\hline
\end{tabular}

Our review findings are organized based on the themes derived from the conceptual framework used during analysis.

Studies included in this review were from diverse geographical settings in SSA: nine studies were conducted in Eastern Africa (Kenya, Burundi, Uganda, and Tanzania); two were conducted in southern Africa (Malawi and Mozambique) and four were conducted in Western Africa (Nigeria and Sierra Leone), and one was a multicountry study that was conducted in Guinea, Benin and the Democratic republic of Congo (Table 2).

\section{Leadership}

We examined the extent to which health committees provided leadership in decision making and how they represented the interests of various community groups. Health committees were mainly involved in making decisions related to day-to-day management of primary health facilities. Two sub-themes emerged under the representation role of health committees. First, representation of various community groups in health committees was influenced by the way these committees were constituted. Second, we found that health committees represented their communities by voicing their concerns about the quality of service delivery.

\section{Representation through selection of health committee members}

Eight of the 15 studies in this review documented how the process of constituting health committees influenced their representation role. There were variations in the way health committees were constituted. They were either constituted through elections or nominated directly by health workers, District health managers and village leaders. In other settings, village leaders selected themselves and fellow elites in the village to be health committee members.
Election of health committee members was reported in three studies. There were however deviations from election norms and procedures that affected representativeness of these committees. Two studies in Kenya and Burundi reported lack of transparency in the election process. Goodman et al. [14] found that existing chairs of health committees, in the coastal part of Kenya, were automatically selected to continue being committee members. As a result of lacking transparency, these members got away with retaining their positions perpetually. Since the election of committee members was not clear to community members, the majority of them had never heard of health committees, their members and roles. The same study revealed that $80 \%$ of community members did not know how committee members were elected [14]. Falisse et al. [13] documented how health committees in some Burundian settings had never held elections. Some committee members had not been replaced for up to 7 years without being elected by the communities they were supposed to represent [13]. Lodenstein et al's [16] study on the role of health committees in social accountability in Guinea, DRC and Benin reported that communities elected committee members, but health committee chairpersons reconstituted committee membership immediately after the elections by dropping key members who they perceived as being either incompetent, "too old" or "too uneducated". Committee chairpersons then invited new members into these committees without consulting other members. These actions resulted in internal opposition, tension and apathy among health committee members [16].

In other settings, health committee members were directly nominated without involvement of community members in elections. Two Tanzanian studies reported how government officials, village leaders and primary health workers appointed committee members. Ward-level Officers advertised vacancies in 


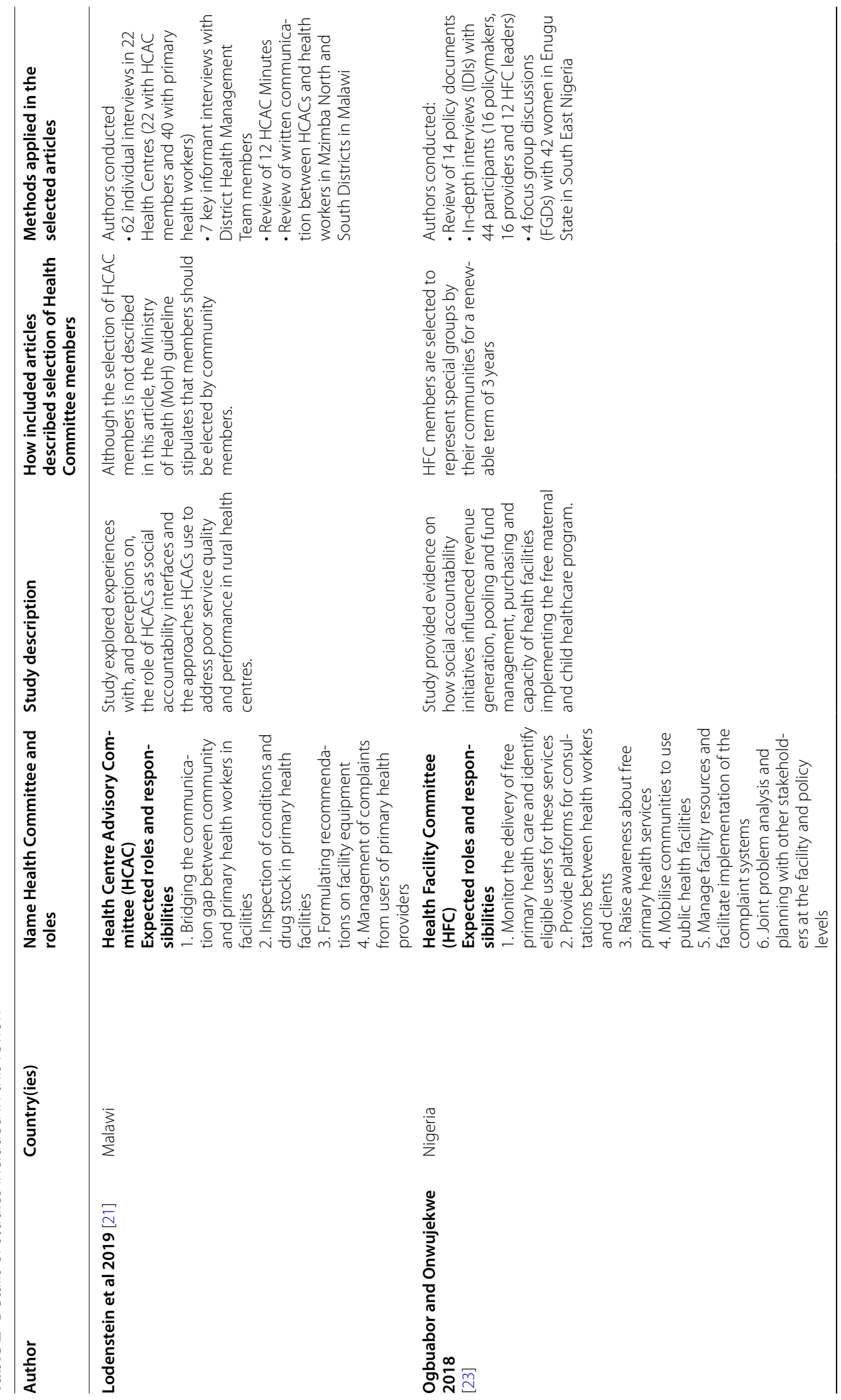




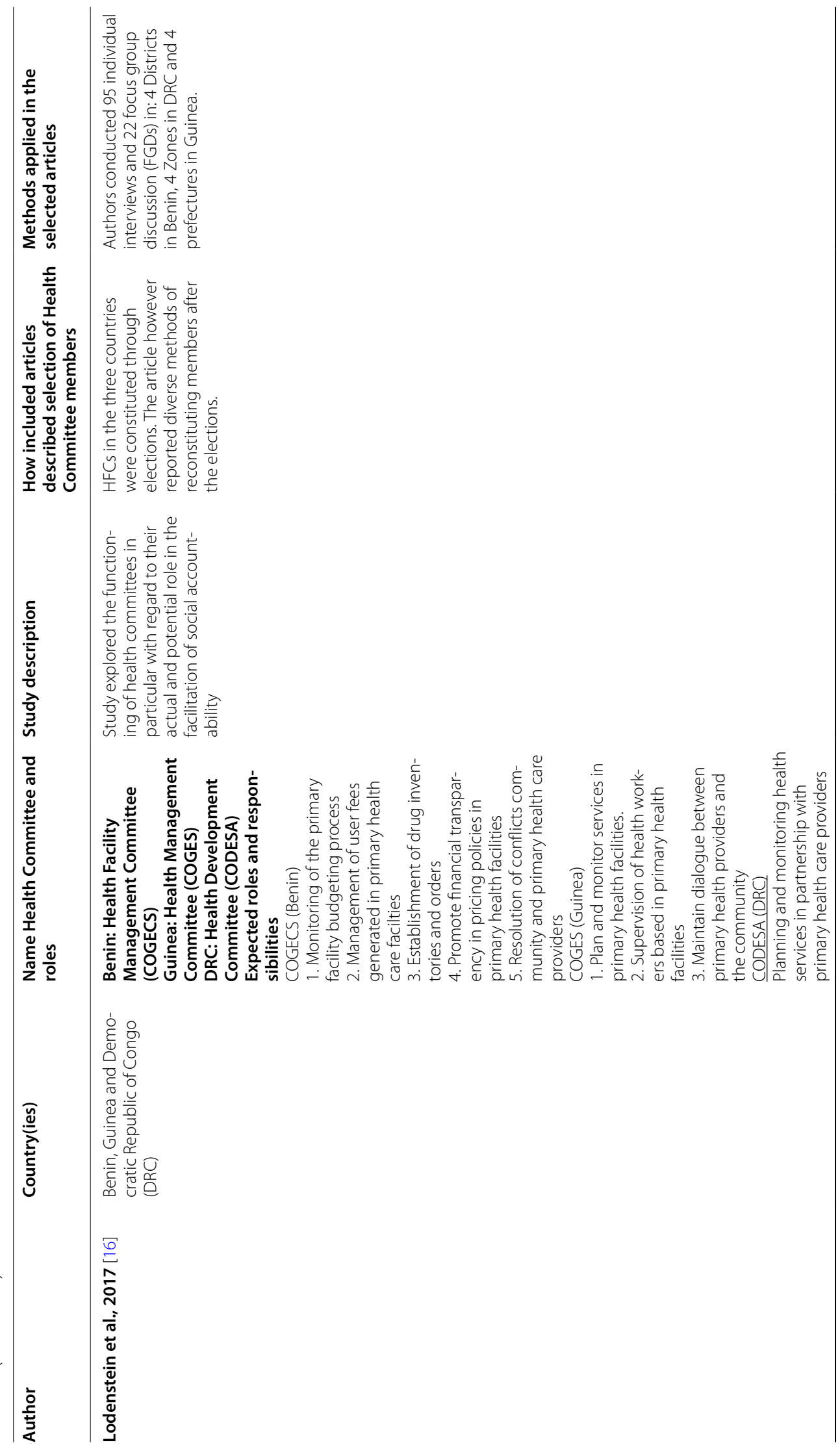




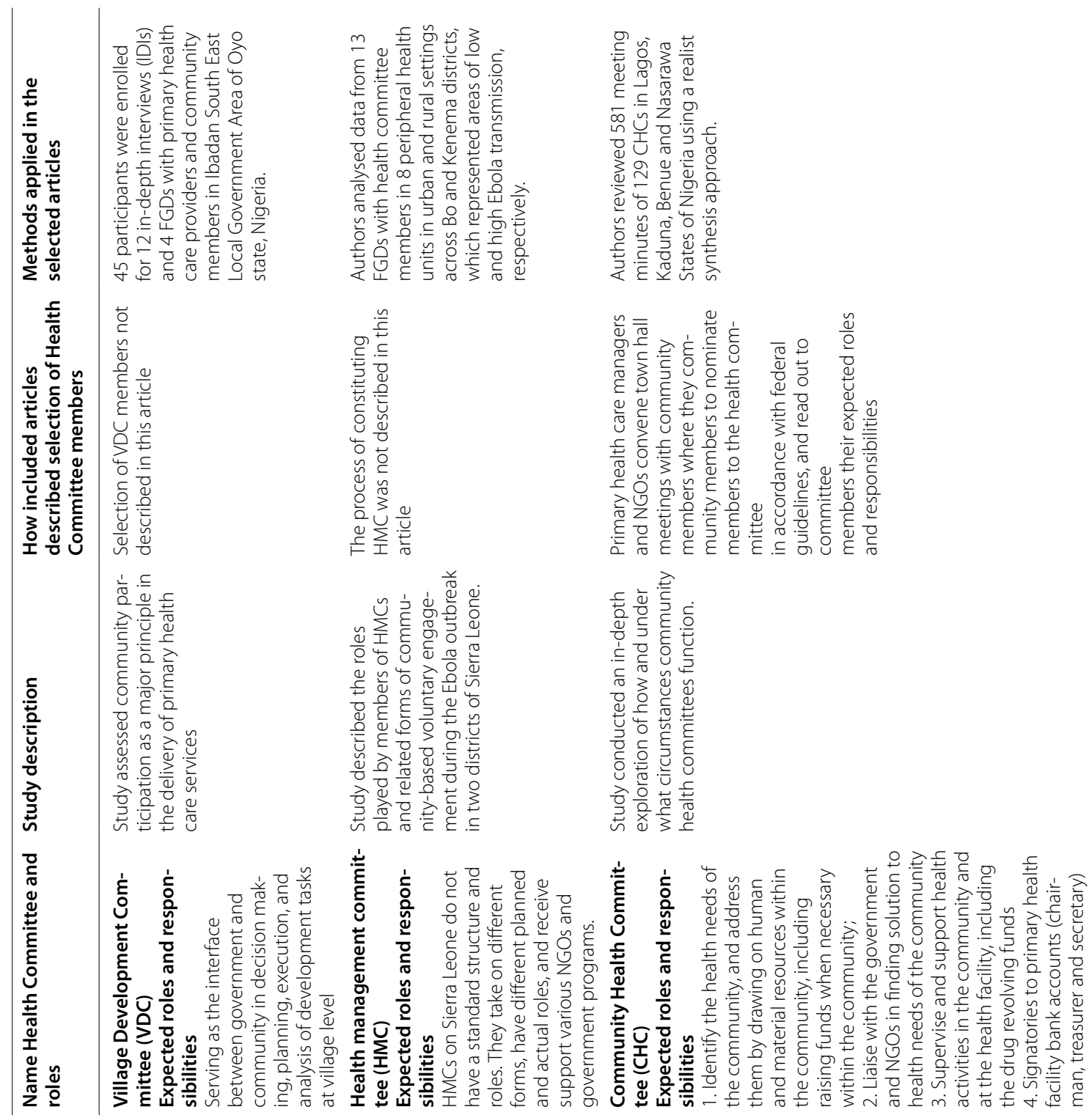

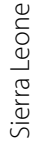

$\frac{\frac{\pi}{\bar{U}}}{\frac{0}{2}}$

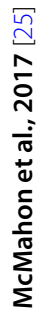

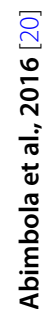




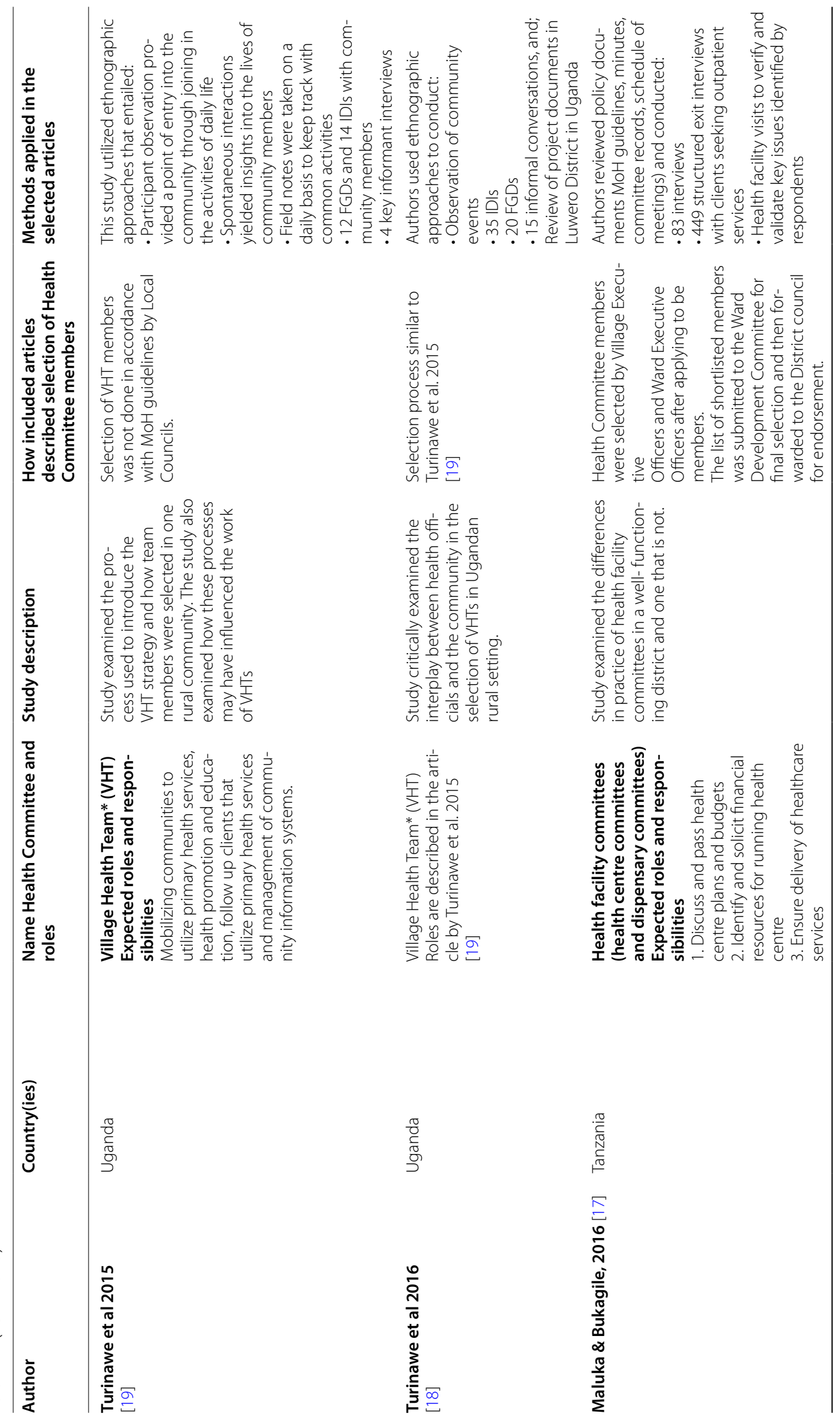




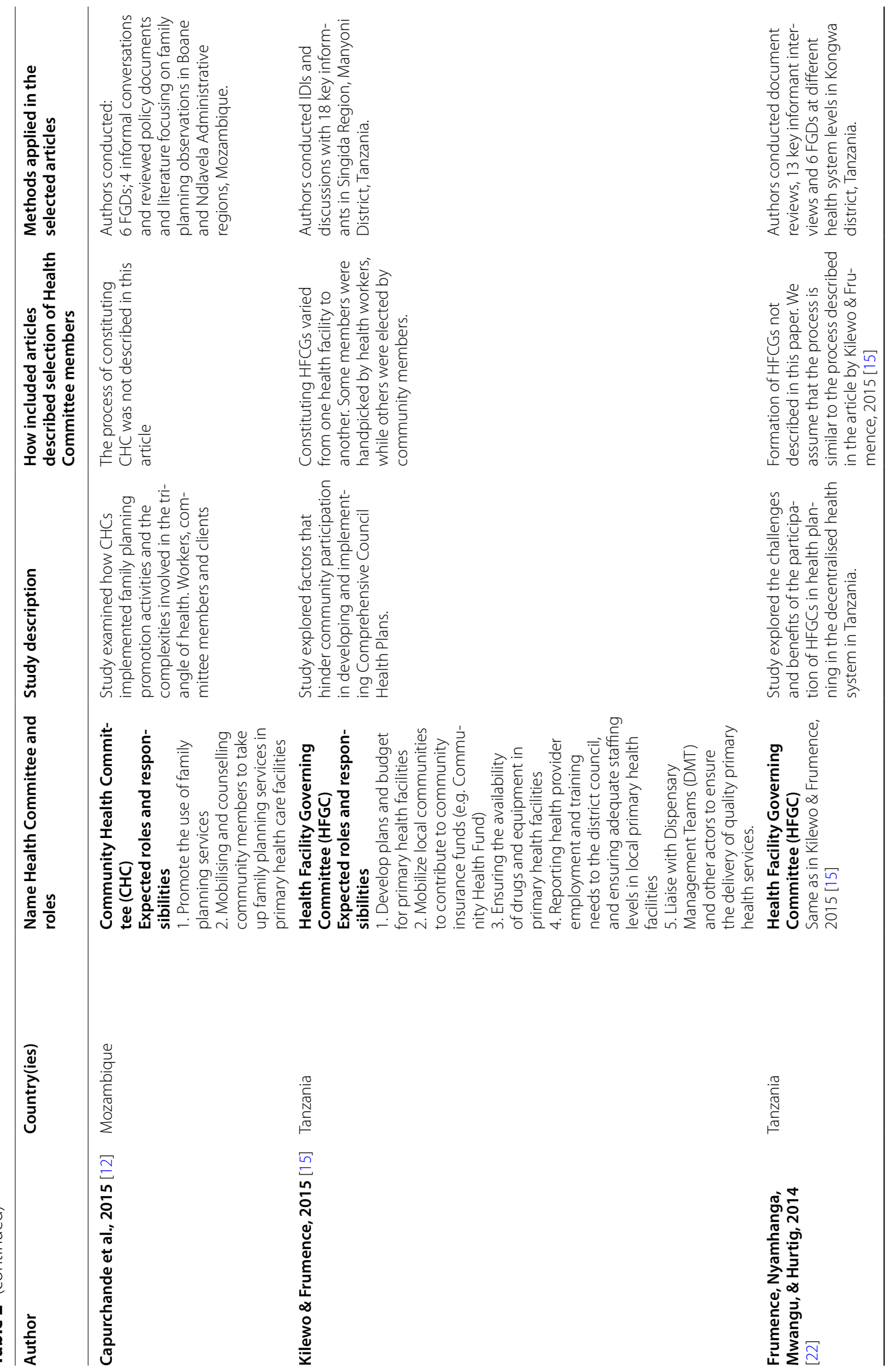



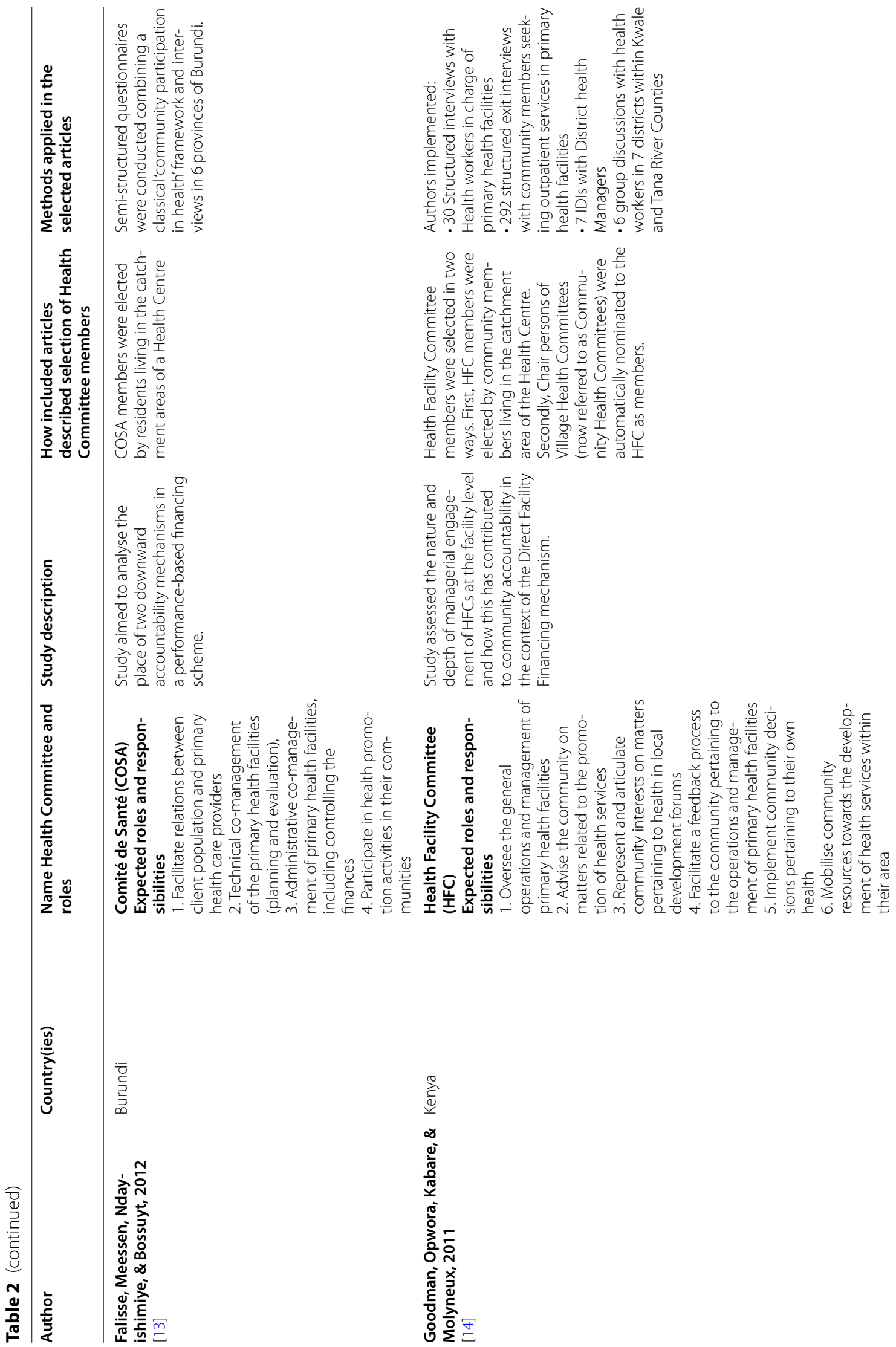


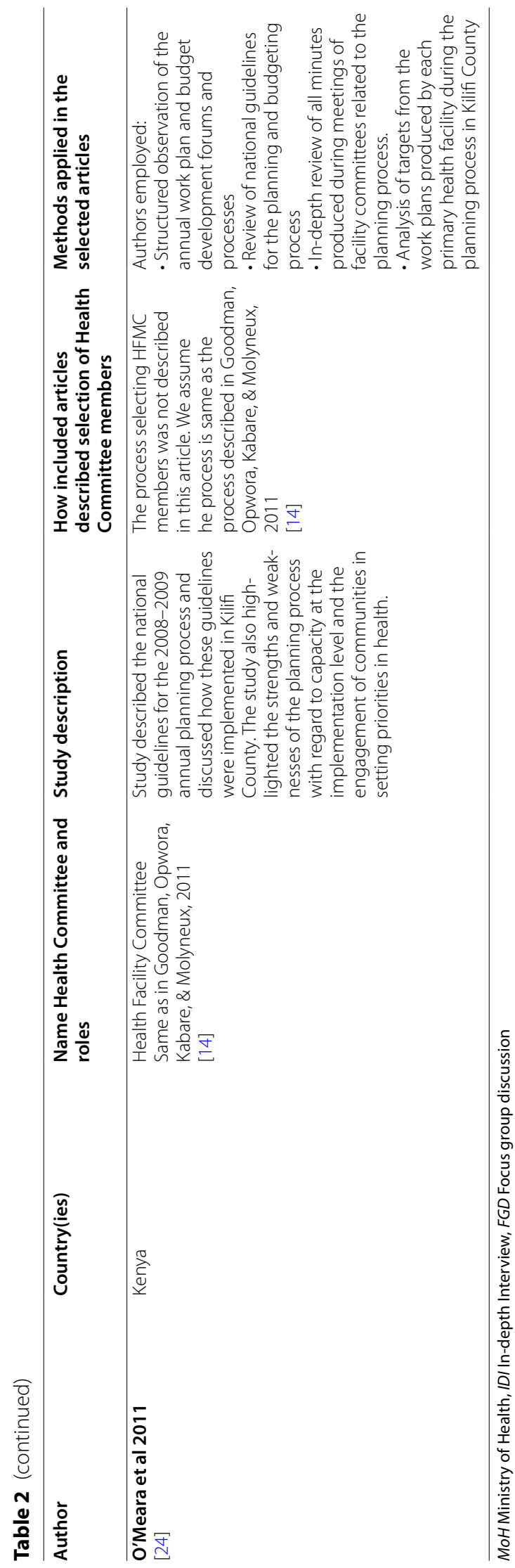


health committees and invited community members who met the eligibility criteria to apply. Applicants were required to be literate and have completed primary education, among others. Ward-level Officers shortlisted the applicants and did the final selection on behalf of District health managers. In most cases, village leaders and health facility in charges directly nominated persons they knew to be part of the health committees. This mode of constitution alienated health committee members from their constituents, who were not aware of the existence of health committees and their roles $[15,17]$. The same was reported in Mozambique, where community health committee members were nominated by health workers and community leaders [12]. Two studies in Uganda showed how village leaders selected themselves and other elite community members into health committees without holding elections. Turinawe et al. (2015) used the term "elite capture" to describe how village council leaders in Uganda influenced the process for selecting Village Health Team (VHT) members. In their desire to wield more power and authority, village council leaders ignored Ministry of Health $(\mathrm{MoH})$ guidelines on the composition of VHTs and appointed themselves, their friends and certain people with formal education without involving other community members. Village council leaders justified not holding elections to constitute VHTs because community members did not show up for such meetings. Two studies in Uganda showed that this mode of constituting VHTs resulted in frustration among community members, suspicion, mistrust, resentment and open hostility towards VHTs by communities $[18,19]$.

A notable observation was that primary health care workers and District health managers in Kenya and Uganda abetted malpractices in the constitution of health committee members. In Uganda, health workers who supervised the composition of VHTs were in favour of village council leaders conveniently selecting people they could "work with" into VHTs. They also did not persuade village council leaders to convene elections [18, 19]. Goodman et al. [14] also demonstrated how sceptical District health managers in Kenya were about the process of electing health committee members by the community. They perceived elected health committee members as "old", illiterate and lacking capacity to manage a health facility. Some District health managers sensitized communities on the importance of electing elite persons in the community such as retired professionals. Election of elite persons in the health committees resulted in intimidation of the less educated committee members [14].
Representation by voicing community concerns about health service delivery

Three studies in Kenya, Malawi and Nigeria documented how health committees represented their communities by actively raising their concerns about the quality of health services to District health authorities. Committee members voiced community concerns about health facility staff that were either abusive, disrespectful or absconded duty, inflated the cost of drugs or failed to be transparent with financial records [14, 20, 21]. In Kenya and Malawi, health committees lobbied District health managers to replace and discipline facility health workers that were involved in misdemeanour. One study described how health committees lobbied district health authorities to provide additional health workers and support staff to facilities. They also lobbied District authorities against transferring of health workers that had a good working relationship with committees and for payment of unremitted health worker allowances and salaries [20].

\section{Management and planning}

In this theme, we explored the extent to which health committee members were involved in managing health services, and defining priorities and budgeting.

\section{Health committees' role in day-to-day management of health facilities}

Six studies conducted in Nigeria, Kenya and Tanzania identified the active role of health committees on the day-to-day decision making and management of primary health facilities. Five of the six studies reported that health committees made decisions regarding the purchase and management of drug stocks, and supervision of projects such as construction and rehabilitation of health facilities. In some cases, health committees made the final decision on the expenditure of user fees that were collected in their health facilities $[15,17,20$, $22,23]$. Two studies conducted in Kenya and Nigeria reported that health committees were responsible for employing and managing support staff (grounds men, security guards, cleaners) in their health facilities [14, 20]. Lodenstein et al's multi-country study described how health committee members in Benin made health workers pledge that they would agree to provide services and charge drugs at set prices. They also made health workers to agree to the working conditions in the presence of District health managers. Health workers who failed to abide by their pledges were disciplined by either being transferred to other areas or dismissal by committee members [16]. Two studies reported improvements in cleanliness and sanitation within 
primary health facilities where health committees participated in day-to-day management $[17,22]$.

Abimbola et al. and Goodman et al. noted cases of conflict between health workers and committee members about management of health facility resources. Conflicts arose when health workers perceived that health committee members were micro-managing them or when committee members demanded for finances from the facility accounts because they perceived themselves as owners and "watch-dogs" of the health facilities $[14,20]$.

\section{Health committees' role in priority setting and budgeting}

Despite health committee involvement in day-to-day management of health facilities, they were often left out in development of annual budgets and plans. Seven studies identified gaps in health committees' participation in setting priorities and making decisions regarding the management of their facilities. In Burundi and Tanzania, health committee members were not aware about the existence of annual primary health plans and budgets. Health committee members also did not know they had a role in the development of these plans and budgets. Committee members reported that none of them had been trained on their management roles [13, 15, 17]. Two other studies conducted in Kenya revealed that health plans and budgets were either developed by facility health workers or by a few health committee officials who had attended the initial committee trainings when health committees were formed with support from a donor-funded project. Overall, health workers actively left out committee members in planning and budgeting for health activities and facilities, because they perceived these committee members as low educated and lacking capacity [14, 17, 22-24]. Three of the seven studies reported that health committees had not been trained on their roles and responsibilities in planning health activities and also lacked budgets to support their involvement in planning (e.g. transport reimbursements, honoraria). These factors affected the performance of health committees in management and planning for health activities and facilities [15, 21, 22].

\section{Resource mobilization}

Overall, six studies documented the role that health committees played in mobilizing resources to support health care delivery through 1) donations and charging user fees, 2) organizing community members to contribute their time, skills and raw materials, and 3) lobbying District managers to post and retain health workers and support staff in their primary health facilities.

Four of the six studies that reported resource mobilization by health committees documented how committee members solicited financial donations from prominent persons in the community and among committee members to undertake projects in their health facilities (construction of wards and health worker accommodation) [21, 25]; clean the health facility; pay for utilities such as water, electricity, minor repairs and pay for meeting costs (transport allowances and refreshments); and employ support staff [17, 22]. Abimbola et al. (2016) observed that health committees mobilized financial resources hoping that the government would supplement their resource mobilization efforts by "topping up" what they collected [20]. There were mixed findings about health committees' role in raising financial resources through user fees. In Goodman et al's [14] study, some committees were not allowed to set user fees because only the MoH had that mandate, while others were free to set their own user fees. Health committees in Abimbola et al's [20] study sold facility supplies that they had received from government and non-government sources to clients seeking primary health care. Committees used finances generated from these sales to pay for utilities (electricity, water), repair and pay themselves meeting allowances [20].

Health committees also mobilized non-financial resources to support health care delivery and projects. In two studies in Tanzania and Nigeria, health committee members organized community members to contribute their labour, time and skills for the construction of health facility infrastructure, such as wards and placenta-pits, and cleaning health facilities $[22,23]$.

\section{Monitoring and evaluation}

Our assessment did not find studies that documented health committee involvement in participatory evaluation. Instead, health committee members monitored the quality of care by health workers, drug stocks and financial records in the facility.

Five articles identified health committees' role in monitoring the quality of health care by health workers in two ways. First, health committees received complaints from community members about quality of services in the facilities, lateness and absenteeism by health workers, denial of care and patient abuse and reporting them to the local health authorities. In one Nigerian study health worker salaries were not paid until the chair of the health committee endorsed the "staff time book" to curtail health worker absenteeism [23]. In another study from Nigeria, health committees required health workers to display a duty roster and weekly schedule of activities on their notice board to ensure that clients knew when to expect what services [20]. Committee members collected information through direct observation of services, inspecting health facilities and interacting with health facility clients [16, 20, 21, 23]. Maluka et al. (2016) 
reported that health services improved after health committees disciplined abusive health workers by having them transferred [17].

Secondly, health committees actively monitored drug stocks delivered to facilities, supplies delivered for facility renovations and also checked the veracity of financial records [16, 20, 22]. Committee members would then report any malpractices for disciplinary action to either District authorities or non-government actors that were supporting health facility projects. Lodenstein et al. [16] reported that health committees in West African settings introduced regulations to make health workers who issued false bills to refund the monies obtained fraudulently back to the health facility. Failure to comply with these regulations led to transfers of health workers to other facilities [16].

\section{Women involvement}

None of the studies in this review had an in-depth exploration of the extent to which women actively participated in decision-making through health committees. Instead, articles reported the gender composition - number of male and female members. Three studies reported that men dominated membership and leadership in health committees. These studies only focused on how inadequate women's representation was [13, 22, 26]. It is only Capurchande et al's (2015) study in Mozambique where most health committees had slightly more women than men [12].

\section{Discussion}

We set out to synthesize qualitative evidence understand how community members in sub-Sahara Africa participate in primary health care services through health committees. This synthesis provides evidence on the dynamics of community participation in community health programs. In this section, we first provide a summary of the findings, followed by a discussion of the key review findings, some recommendations, and limitations of the study.

Overall, we found that health committees were involved in a number of areas such as: voicing their communities' concerns about the quality of care provided by health facility staff; day-to-day management of health facilities; and mobilizing financial and non-financial resources for health activities and projects. Health committees held health workers accountable by monitoring absenteeism, quality of services and expenditures in health facilities. We identified several challenges that influenced their success. Firstly, health committees lacked legitimacy, because selection procedures were often not transparent and participatory. As a result, communities were not fully aware of the existence of committees and their roles.
Secondly, committee members were often left out in planning and budgeting processes by health workers who perceived them as insufficiently educated and trained to take part in planning. Thirdly, most health committees were dominated by male members, which limited the participation by women in voicing their health priorities. Below, we explore two key factors that influence the operationalization of community participation through health committees. We discuss how power dynamics influence selection of committee members and their involvement in planning and budgeting. We then have an in-depth discussion on tokenism in health committees.

\section{Power dynamics in community participation}

Consistent with existing literature, our review reveals two ways how power dynamics manifest in community participation [27]. First, primary health workers and health managers use their power to influence the composition of health committees. We saw, in a number of settings, that health workers select or influence the election of elite and educated persons to these committees. This modification of selection procedures leads to elite capture and presents opportunities for individuals or elite groups to advance their own interests. Elite capture affects representativeness of health committees, which denies health committees impartiality, public spirit and support that is much needed for community participation [28]. Modification of selection processes without transparent involvement of community members also creates an environment where health committees lack legitimacy and are alienated from their constituents [29,30]. Elite members may not understand the needs of their constituents or may not have similar ethnic or social-economic status as those they represent $[31,32]$. Interestingly, elite members in health committees did lobby district authorities for disciplinary action when primary health workers were abusive or absent, mobilize resources to improve facilities and monitor absenteeism among health workers. It is possible that concerns voiced were those of elite individuals in the community. This was probably because they feel empowered to challenge or talk with those in authority. It is however not clear whether this sense of empowerment could enable them to address issues of importance to the broader community. On the other hand, having a more representative group in the committees might lead to a committee that is less "respected" by local authorities, and less listened-to by health workers as they are not "educated enough".

Second, primary health workers and managers manifest power by dominating and controlling the planning and budgeting processes [27]. This is despite primary health workers and health managers favouring the selection of elites into the committees. Leaving out committee 
members during planning and budgeting processes may be a form of resistance by health workers and managers against community participation. Engaging lay individuals in developing health facility plans, albeit them being elites, is a shift from the traditional physician-dominated, biomedical illness-care system and tensions arise when health workers feel threatened by potential reduction of influence and control to lay committee members [31]. Previous research shows that health professionals tend to place more importance to formal education and specialized skills and undervalue local knowledge possessed by health committee members, despite some of them being relatively more educated. While technical expertise is needed in management of community health, it must be accompanied by local knowledge (history, culture, gender and power relations, terrain, geo-politics) for it to suit the communities' needs [33]. Health workers and managers in Shayo et al.s [34] study believed that involving lay health committee members in planning would lead to uninformed decisions and fail to yield desired results. Consistent with our review findings, literature supports that health professionals believe that lay community members would not grasp the complex clinical and administrative aspects of health being discussed [34-36], thus limiting the participation of communities in making decisions on matters that affected their health.

\section{Tokenistic participation}

Tokenistic participation implies that community members are heard and allowed to argue about decisions regarding their health, but there is no guarantee that their contributions will be considered by health professionals [37]. It is widely accepted that inclusion of community members, especially marginalized groups, in making decisions about their health is crucial for them to have greater control in determining how these services are delivered. There is, however, inadequate understanding of the best way of ensuring both implicit and explicit inclusion. There is need for empirical evidence to answer the question whether inclusion will be enhanced by asking more marginalized groups to participate or whether the more influential individuals should be sensitized on how to represent marginalized groups. For example, we noted that some studies in this review only reported the number of women in health committees. Women's contribution to decision-making was not explored in any of these studies. Existing literature shows that underlying contextual factors and culture influence the extent to which women participate in health committees. In some settings, tokenism in women's participation in health committees is driven by androcentric and patriarchal ideologies [38, 39]. Shayo et al. [34] studied the patriarchal tendencies that limit women's participation in health committees. First, women were not listened to and do not occupy leadership positions. This also holds a risk that women's needs are not well represented in health committees, because they are perceived not to have gained sufficient confidence in presenting strong points during meetings. Second, male committee members were sceptical and did not trust in women's abilities in decision making [34].. Tokenistic inclusion of women and patriarchy constrain equitable participation and gender parity in decision making structures, despite the existence of polices to promote equal and equitable gender representation.

Using the Draper et al., framework, we attempted to characterize the extent of participation in the continuum of community participation, which ranges from mobilization, collaboration to empowerment. Overall, leadership by health committees is situated on the mobilization end of the continuum because health professionals in several contexts assume the role of constituting health committees. The same health professionals did not hold "elite" members accountable whenever they contravened health committee selection guidelines when constituting health committees. On the other hand, health committees were more collaborative when voicing communities' grievances about the quality of care to health workers. Participation of health committees in management of health services is largely in the mobilization end of the continuum. Health workers decided on the health activity plans and annual health budgets for the health centres and community health without involving health committee members. Day-to-day management and decision making about drug stocks, cleanliness and employment of support staff are in the collaborative end of the continuum of participation. Our findings suggest that resource mobilization by health committees in subSahara Africa is situated in the collaborative point of the participation continuum because they mainly get their resources by seeking donations for materials and labour from their communities. They also raised funds for running their facilities by lobbying influential members in society to make financial contributions. Recent research suggests that health committees can be strengthened to effectively play their roles in leadership and management by building their capacity and providing them with regular technical support [40]. We did not find adequate empirical literature of how health committees sought to promote the participation of women in health committees. Also did not find literature on the involvement of health committees in participatory evaluation of community health programs. Generally, documentation of participatory evaluation of community level primary health programs is lacking or inadequate [41]. We interpret that both participation of women and participation of health 
committees in participatory evaluation are towards the mobilization end of the community participation spectrum.

\section{Recommendations}

Our review brings out key issues that influence how health committees participate in primary and community health. We propose three recommendations for strengthening community participation through health committees. First, for health committees to be respected and legitimate representatives of their communities, the mode and procedures for selecting members must be seen to create political legitimacy and procedural justice [28]. Second, health workers and managers need supportive supervision and capacity building in team management. This may help to address fears of "relinquishing" power by allowing communities to participate in development of health plans. Health workers also need to be sensitized on the value of social inclusion and diversity in the composition of health committees. Third, it may be time to update community health strategies in sub-Sahara African countries to reflect the realities of community participation identified in this review. These updates need to acknowledge the inherent strengths of health committees and address the challenges of power and degree of participation in decision making by communities and marginalized groups.

\section{Limitations}

This review has some limitations. Our literature search only included studies published after 2008 and only in English, it is possible that we precluded earlier in-depth explorations on community participation through health committees or studies in other languages. A key strength in this study was that selection of studies was performed by two authors. Analysis and interpretation of the findings was reviewed by three authors. Agreement on the interpretations drawn from the studies was arrived at through consensus. The Draper et al. framework was useful while extracting and interpreting data from the literature, despite data on some components of the framework being scarce. We also recognize that the Draper et al. framework does not focus on the analysis of how specific marginalized groups participate in decision-making through health committees. We recommend additional and in-depth analysis of contextual factors that contextual that influence community participation.

\section{Conclusion}

Our study shows that health committees are viable mechanisms for community participation. However, there is need for transformational change in the practice of community participation [42]. Decision makers, health managers and advocates need to fundamentally rethink how health committees are selected, empowered and supported to implement their roles and responsibilities. There is also need to support health workers to have a more positive stand towards health committees by sensitizing them about the value of community participation in health. These insights can help health workers and decision makers to update guidelines on community participation by providing a synthesis of key issues that influence how health committees participate in health.

\section{Abbreviations \\ CHC: Community Health Committee; COSA: Comité de Santé; FGD: Focus group discussion; HCAC: Health Centre Advisory Committee; HFC: Health Facility Committee; HFCG: Health Facility Governing Com- mittee; HMC: Health management committee; IDI: In-depth Interview; MoH: Ministry of Health,; VDC: Village Development Committee; VHT: Village Health Team.}

\section{Supplementary Information}

The online version contains supplementary material available at https://doi. org/10.1186/s12889-022-12730-y.

Additional file 1: Supplementary file 1: Search terms applied in the three online databases. Supplementary file 1 contains all the search terms that we applied while searching for relevant articles in the MEDLINE, CINAHL and Popline data bases.

\section{Acknowledgements}

Not applicable

\section{Authors' contributions}

The search strategy was developed by ML and RK, in discussion with MK and MD. The search, data extraction and synthesis were conducted by RK and ML. The first draft of the paper was prepared by RK and ML, with major contributions in the synthesis and writing from JB, PM, MK, ML, MD and RK. All authors made significant contributions to this manuscript and approved the manuscript as submitted.

\section{Funding}

No funding.

\section{Availability of data and materials}

All data that were analysed are included in this published article and its supplementary information files.

\section{Declarations}

Ethics approval and consent to participate

No ethics approval and consent to participate was required for this study.

Consent for publication

Not applicable.

Competing interests

The authors declare that they have no competing interests.

Author details

${ }^{1}$ LVCT Health, P.O. Box 19835, Nairobi 00202, Kenya. ${ }^{2}$ Athena Institute, Vrije Universiteit Amsterdam, De Boelelaan 1085, 1081 HV Amsterdam, The Netherlands. ${ }^{3}$ KIT Royal Tropical Institute, Mauritskade 63, 1092 AD Amsterdam, Netherlands. ${ }^{4}$ Jomo Kenyatta University of Agriculture and Technology, P.O. Box 62000, Nairobi 00200, Kenya. 
Received: 4 November 2020 Accepted: 7 February 2022

Published online: 19 February 2022

\section{References}

1. McCoy DC, Hall JA, Ridge M. A systematic review of the literature for evidence on health facility committees in low- and middle-income countries. Health Policy Plan. 2012;27(6):449-66.

2. World Health Organization. WHO recommendation on community participation in programme planning and implementation. Geneva:WHO Reproductive Health Library; 2015.

3. Boulle T. A review of the functioning of health committees in Nelson Mandela Bay Health District University of Cape Town; 2013.

4. Aga Khan Health Services. Health Facility Committees: The Governance Issue; Community Health Services. Nairobi: AKHS; 2005.

5. Loewenson R, Rusike I, Zulu M. Assessing the impact of health centre committees on health system performance and health resource allocation. Harare: EQUINET; 2004

6. Sohani S. Health care access of the very poor in Kenya. DFID workshop - meeting the health related needs of the very poor workshop paper 11; 2005.

7. Marston C, Hinton R, Kean S, Baral S, Ahuja A, Costello A, et al. Community participation for transformative action on women's, children's and adolescents' health. Bull World Health Organ. 2016:94(5):376-82.

8. Walley J, Lawn JE, Tinker A, de Francisco A, Chopra M, Rudan I, et al. Primary health care: making Alma-Ata a reality. Lancet (London, England). 2008;372(9642):1001-7.

9. Draper A, Hewitt G, Rifkin S. Chasing the dragon: developing indicators for the assessment of community participation in health programmes. Soc $\mathrm{SC}$ Med. 1982;2010(71):1102-9.

10. Flemming K, Booth A, Garside R, Tunçalp Ö, Noyes J. Qualitative evidence synthesis for complex interventions and guideline development: clarification of the purpose, designs and relevant methods. BMJ Glob Health. 2019:4(Suppl 1):e000882.

11. JBI. Joanna Briggs institute reviewers' manual. Australia: The Joanna Briggs Institute; 2016

12. Capurchande RD, Coene G, Roelens K, Meulemans H. Between compliance and resistance: exploring discourses on family planning in community health committees in Mozambique. BMJ Open. 2015;5(5):e006529.

13. Falisse JB, Meessen B, Ndayishimiye J, Bossuyt M. Community participation and voice mechanisms under performance-based financing schemes in Burundi. Trop Med Int Health. 2012;17(5):674-82.

14. Goodman C, Opwora A, Kabare M, Molyneux S. Health facility committees and facility management - exploring the nature and depth of their roles in Coast Province, Kenya. BMC Health Serv Res. 2011;11:229.

15. Kilewo EG, Frumence G. Factors that hinder community participation in developing and implementing comprehensive council health plans in Manyoni District, Tanzania. Glob Health Action. 2015;8:26461.

16. Lodenstein E, Mafuta E, Kpatchavi AC, Servais J, Dieleman M, Broerse JEW, et al. Social accountability in primary health care in west and Central Africa: exploring the role of health facility committees. BMC Health Serv Res. 2017;17(1):403.

17. Maluka SO, Bukagile G. Community participation in the decentralised district health systems in Tanzania: why do some health committees perform better than others? Int J Health Plann Manage. 2016;31(2):E86-e104.

18. Turinawe EB. 'Those were taken away and given money': power and reward expectations' influence in the selection of village health teams in rural Uganda. Rural Remote Health. 2016;16(2):3856.

19. Turinawe EB, Rwemisisi JT, Musinguzi LK, de Groot M, Muhangi D, de Vries $\mathrm{DH}$, et al. Selection and performance of village health teams (VHTs) in Uganda: lessons from the natural helper model of health promotion. Hum Resour Health. 2015:13:73.

20. Abimbola S, Molemodile SK, Okonkwo OA, Negin J, Jan S, Martiniuk AL.'The government cannot do it all alone': realist analysis of the minutes of community health committee meetings in Nigeria. Health Policy Plan. 2016;31(3):332-45.

21. Lodenstein E, Molenaar JM, Ingemann C, Botha K, Mkandawire JJ, Liem L, et al. "We come as friends": approaches to social accountability by health committees in northern Malawi. BMC Health Serv Res. 2019;19(1):279.

22. Frumence $G$, Nyamhanga T, Mwangu M, Hurtig AK. Participation in health planning in a decentralised health system: experiences from facility governing committees in the Kongwa district of Tanzania. Glob Public Health. 2014:9(10):1125-38
23. Ogbuabor DC, Onwujekwe OE. The community is just a small circle: citizen participation in the free maternal and child healthcare programme of Enugu state, Nigeria. Glob Health Action. 2018;11(1):1421002.

24. O'Meara WP, Tsofa B, Molyneux S, Goodman C, McKenzie FE. Community and facility-level engagement in planning and budgeting for the government health sector--a district perspective from Kenya. Health Policy (Amsterdam, Netherlands). 2011;99(3):234-43.

25. McMahon SA, Ho LS, Scott K, Brown H, Miller L, Ratnayake R, et al. "We and the nurses are now working with one voice": how community leaders and health committee members describe their role in Sierra Leone's Ebola response. BMC Health Serv Res. 2017;17(1):495.

26. Iyanda OF, Akinyemi OO. Our chairman is very efficient: community participation in the delivery of primary health care in Ibadan, Southwest Nigeria. Pan Afr Med J. 2017:27:258

27. Ocloo J, Matthews R. From tokenism to empowerment: progressing patient and public involvement in healthcare improvement. BMJ Qual Saf. 2016;25(8):626-32.

28. Meier BM, Pardue C, London L. Implementing community participation through legislative reform: a study of the policy framework for community participation in the Western cape province of South Africa. BMC Int Health Hum Rights. 2012;12(1):15

29. Zwama G, Stuttaford MC, Haricharan HJ, London L. Rights-based training enhancing engagement of health providers with communities, cape metropole, South Africa. Front Sociol. 2019;4:1-12. https://doi.org/10.3389/fsoc. 2019.00035.

30. Church J, Saunders D, Wanke M, Pong R, Spooner C, Dorgan M. Citizen participation in health decision-making: past experience and future prospects. J Public Health Policy. 2002;23(1):12-32.

31. Frankish CJ, Kwan B, Ratner PA, Higgins JW, Larsen C. Challenges of citizen participation in regional health authorities. Soc Sci Med. 2002:54(10):1471-80.

32. Martin GP.'Ordinary people only': knowledge, representativeness, and the publics of public participation in healthcare. Sociol Health IIIn. 2008;30(1):35-54

33. Baatiema L, Skovdal M, Rifkin S, Campbell C. Assessing participation in a community-based health planning and services programme in Ghana. BMC Health Serv Res. 2013;13:233

34. Shayo EH, Norheim OF, Mboera LEG, Byskov J, Maluka S, Kamuzora P, et al. Challenges to fair decision-making processes in the context of health care services: a qualitative assessment from Tanzania. Int J Equity Health. 2012;11(1):30

35. Bruni RA, Laupacis A, Martin DK. University of Toronto Priority setting in health care research $\mathrm{G}$. public engagement in setting priorities in health care. CMAJ. 2008;179(1):15-8.

36. Morrison C, Dearden A. Beyond tokenistic participation: using representational artefacts to enable meaningful public participation in health service design. Health Policy. 2013;112(3):179-86

37. Gaber J. Building "a ladder of citizen participation": Sherry Arnstein, citizen participation, and model cities. J Am Plann Assoc. 2019:85:1-14.

38. Lindemann $\mathrm{H}$. The woman question in medicine: an update. Hastings Cent Rep. 2012:42(3):38-45.

39. Rawat PS. Patriarchal beliefs, women's empowerment, and general wellbeing. Vikalpa. 2014:39(2):43-56

40. Karuga RN, Kok M, Mbindyo P, Hilverda F, Otiso L, Kavoo D, et al. "It's like these CHCs don't exist, are they featured anywhere?": social network analysis of community health committees in a rural and urban setting in Kenya. PLoS One. 2019:14(8):e0220836.

41. Cordero J, Gichangi P, Smit J, Nkole T, Kiarie J, Temmerman M. Participatory approaches involving community and healthcare providers in family planning/contraceptive information and service provision: a scoping review. Reprod Health. 2016;13:88. https://doi.org/10.1186/s12978-016-0198-9.

42. Dougall $D$, Lewis $M$, Ross S. Transformational change in health and care: reports from the field. London: The King's Fund; 2018. p. 104.

\section{Publisher's Note}

Springer Nature remains neutral with regard to jurisdictional claims in published maps and institutional affiliations. 